\title{
Effects of a combination of 3,4-methylenedioxymeth amphetamine and caffeine on real time stimulated dopamine release in the rat striatum: studies using fast cyclic voltammetry
}

\author{
1, 2O'Connor, J.J., ' ${ }^{2}$ 'Boyle, K.M. ${ }^{1}$ Lowry, J.P. \\ ${ }^{1}$ Department of Chemistry, Maynooth University, \\ Maynooth, Co. Kildare, Ireland. ${ }^{2}$ UCD School of \\ Biomolecular \& Biomedical Science, UCD Conway \\ Institute, Belfield, Dublin 4, Ireland. \\ Corresponding Author: \\ John J O'Connor, \\ UCD School of Biomolecular \& Biomedical Science, UCD \\ Conway Institute, Belfield, Dublin 4, Ireland \\ Tel: 0035317166765 \\ Email: john.oconnor@ucd.ie
}

\begin{abstract}
It is well documented that caffeine exacerbates the hyperthermia associated with acute exposure to 3,4-methylenedioxymethamphetamine (MDMA) in rats. Previous reports have also indicated that MDMA-related enhancement of dopamine release is exacerbated in the presence of caffeine. In the present study we have examined whether the effects of MDMA on real-time stimulated dopamine release in the absence of uptake inhibition are accentuated in the presence of caffeine. Isolated striatal slices from adult male Wistar rats were treated acutely with MDMA, caffeine, or a combination, and their effects on single and 5 pulse stimulated dopamine release monitored using the technique of fast cyclic voltammetry. Caffeine at 10 or $100 \mu \mathrm{M}$ had no significant effect on single pulse stimulated dopamine release. However $100 \mu \mathrm{M}$ caffeine caused a significant peak increase in 5 pulse stimulated dopamine release. Both 1 and $30 \mu \mathrm{M}$ MDMA gave rise to a significant increase in both single and 5-pulse dopamine release and reuptake. A combination of $100 \mu \mathrm{M}$ caffeine and 1 or $30 \mu \mathrm{M}$ MDMA did not significantly enhance the effects of MDMA on single or 5 pulse dopamine release and reuptake when compared to that applied alone. Utilizing single action potential dependent dopamine release, these results do not demonstrate a caffeine-enhanced MDMA-induced dopamine release.
\end{abstract}

Key words: Caffeine, MDMA, real time dopamine release, cyclic voltammetry, single pulse, rat striatum.

Abbreviations: 3,4-methylenedioxymethamphetamine, MDMA; 5-HT, serotonin; artifical cerebrospinal fluid, aCSF; fast cyclic voltammetry, FCV

\section{INTRODUCTION}

3,4-methylenedioxymethampetamine (MDMA) or ecstasy is a popular synthetic drug of abuse, which has many neuropharmacological activities including those on the serotonergic and dopaminergic systems in the CNS (Green et al., 2003). MDMA inhibits the reuptake of $5-\mathrm{HT}$, facilitates serotonin release, and causes the release of dopamine and noradrenaline (Lyles and Cadet, 2003). Therefore MDMA increases the amount of extracellular serotonin and dopamine, a mechanism thought to involve at least partially, the reversal of the membrane serotonin and dopamine transporters (SERT and DAT respectively; Green et al., 1995; Crespi et al., 1997; Iravani et al., 2000). Numerous investigators have confirmed the dopaminereleasing actions of MDMA using tritiated dopamine (Johnson et al., 1986, Fitzgerald \& Reid, 1990), in vivo microdialysis (Gudelsky et al., 1994) and voltammetry (John \& Jones, 2007; Iravani et al., 2000). Thus the acute effects of MDMA on brain monoamines may result from the ability of the drug to modulate 5-HT and dopamine release and reuptake (Johnson et al., 1986). Also, long-term exposure to MDMA may cause a selective decrease in brain concentrations of 5-HT and dopamine, possibly due to loss of 5-HT and dopamine nerve terminals in various brain regions (Green et al., 1995).

Caffeine is probably the most highly consumed psychoactive drug in the world and also has acute effects on dopamine release (Reith et al., 1987). It is a non-selective adenosine receptor antagonist that targets mainly adenosine $A_{1}$ and $A_{2 a}$ receptors in the brain (Okada et al., 1997; Solinas et al., 2002; Quarta et al., 2004; Ferre et al., 2008a,b). We have previously shown that adenosine $A_{1}$ receptor mediated inhibition of dopamine release from rat striatal slices is modulated by $D_{1}$ dopamine receptors (O'Neill et al., 2007). Several studies have shown that adenosine and dopamine receptors do not function independently of each other, but rather interact with each other at a number of levels (Ferre et al., 2008a,b; Mango et al., 2014). Antagonistic interactions have been demonstrated between $A_{1}$ and $D_{1}$ and $A_{2 a}$ and $D_{2}$ dopamine receptors (O'Neill et al., 2007). However the extent to which these interactions between adenosine and dopamine receptors affect the regulation of dopamine release is still unknown.

Previous studies have indicated a number of neurotoxic effects of the combination of MDMA and caffeine in the brain (Derlet et al., 1992; Ikeda et al., 2011 and reviewed in Vanattou-Saïfoudine et al., (2010a)). In rats, caffeine acts synergistically with MDMA in producing hyperthermia (VanattouSaifoudine et al., 2010a. 2010b; McNamara et al., 2006; O'Loinsigh et al., 2001), changes in locomotion (Antoniou et al., 2005) and dopamine release (Vanattou-Saifoudine et al., 2011, Sinchai et al., 2011). Taken together, all of these reports support the view that caffeine facilitates acute and indeed long-term toxicity associated with MDMA.

Most of these studies to date have used long durations of continuous stimulation, electrical and chemical, to evoke dopamine release and often in the presence of dopamine uptake inhibitors in order to be able to measure sufficient dopamine levels. For example in most microdialysis studies electrical and chemical stimuli protocols can last for many 
seconds and thus activate many receptor subtypes including autoreceptors. In this study we have used an alternative study protocol to previous work utilizing discrete single short-term stimuli evoking single and multiple action potentials presynaptically. The temporal resolution of fast cyclic voltammetry, applied at up to 100 scans per second ('real-time' measurement), can monitor the release of dopamine at the sub-second level (O'Connor \& Lowry, 2012). In this study we compared a single (0.1ms) stimulus to a 5-pulse (at $10 \mathrm{~Hz}$, lasting 400ms) stimulus and monitored dopamine release every $250 \mathrm{~ms}$. We show modulatory effects of both caffeine and MDMA on single and 5 pulse dopamine release. However under minimal pulse stimulation and in the absence of dopamine reuptake inhibitors, we demonstrate that acute MDMA-induced dopamine release is not enhanced in the presence of caffeine.

\section{MATERIALS AND METHODS \\ 2.1. Experimental Preparation \\ 2.1.1. Brain slices}

Male Wistar rats (178-283g), housed 4 to a cage, were purchased by Maynooth University, fortnightly from Harlan, UK and kept in the BioResources Unit in Maynooth. All experiments were carried out in accordance with the guidlines of the animal ethics committe of NUIM and the European Communities Council Directive of 24 November 1986 (86/609/EEC). Rats were killed by decapitation. The brain was quickly removed into ice-cold artifical cerebrospinal fluid (aCSF). Blocks of tissue containing the caudate putamen and nucleus accumbens were prepared. $350 \mu \mathrm{m}$ thick slices were sectioned using a Campden vibrotome. Brain slices were then transferred to a holding chamber containing aCSF (see below) at room temperature $\left(20-21^{\circ} \mathrm{C}\right)$ to equilibrate for $1 \mathrm{~h}$. A single slice was then transferred to a recording chamber and superfused with oxygenated aCSF at $4 \mathrm{ml}^{\mathrm{min}} \mathrm{m}^{-1}$ at $30-31^{\circ} \mathrm{C}$ for 40 min before electrical stimulation.

\subsubsection{Measurement of endogenous dopamine} release

Following 40 min equilibration, a bipolar tungstenstimulating electrode with a tip separation of 200 $\mu \mathrm{m}$ (A-M Systems, Inc.) was placed in the dorsolateral caudate putamen (see Figure 1). A carbon fiber electrode ( $7 \mu \mathrm{m}$ diameter carbon fiber; 50-100 $\mu \mathrm{m}$ exposed length) was placed 100-200 $\mu \mathrm{m}$ from the stimulating microelectrode. Fast cyclic voltammetry (FCV; Millar Voltammeter; Dr. Julian Millar, Queen Mary \& Westfield College, University of London, UK) at the carbon fiber electrode was used to detect changes in extracellular concentrations of dopamine following electrical stimulation of the brain slice (Palij et al., 1990). A basic triphasic voltage waveform (ranging from -1.0 to $+1.0 \mathrm{~V}$; 20 ms duration), generated using a Millar voltammeter (Millar \& Barnett, 1988) was applied to the carbon fiber electrode at $4 \mathrm{~Hz}$ (every $250 \mathrm{~ms}$; Figure $1 \mathrm{~A})$. This waveform was modified from our 'extended' waveform (-1.0 to $+1.4 \mathrm{~V}$; see Stamford, 1990) where MDMA is electroactive, producing oxidation currents that interfere with the oxidative currents for dopamine. Using the basic waveform
MDMA is electrochemically inert whilst the sensitivity of FCV to dopamine is maintained (see Irivani et al., 2000). A sample and hold device built into the Millar voltammetry monitored dopamine release at $+610 \mathrm{mV}$ during each scan (Figure 1B, C). Stimulated dopamine release (using Neurolog modules) was evoked using a square-wave pulse of $10 \mathrm{~V}$ amplitude and $100 \mu$ s duration delivered once every 2 min (O'Connor \& Lowry, 2012).
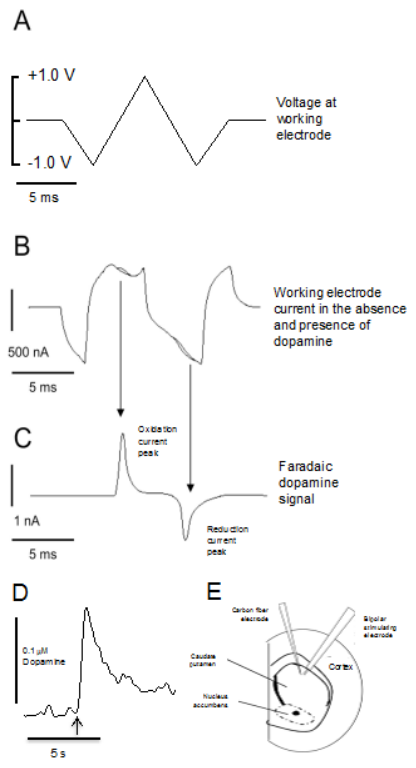

Figure 1 Waveforms used in FCV

A. A triphasic voltage ramp is passed down the carbon fiber electrode twice per second. The ramp sweeps from 0 $\mathrm{V}$ (relative to silver/silver chloride reference electrode) to $1.0 \mathrm{~V}$ to $+1.0 \mathrm{~V}$ to $-1.0 \mathrm{~V}$ and back to $0 \mathrm{~V}$. This sweep lasts $20 \mathrm{~ms}$. B. The resultant current measured by the carbon fiber electrode in called the charging current. Superimposed on the charging current is the current obtained when the electrode is placed in aCSF solution containing $1 \mu \mathrm{M}$ dopamine. C. If the charging current in B in the absence of dopamine is subtracted from the current in the presence of dopamine a trace typical of $C$ is the result (subtraction voltammogram). This is known as the faradaic current and is the result of the oxidation and reduction of dopamine on the surface of the carbon fiber electrode. Dopamine oxidizes at approximately $+610 \mathrm{mV}$ and is reduced at $-200 \mathrm{mV}$.

D. The trace illustrated in $D$ is the result of a sample and hold device measuring at $+612 \mathrm{mV}$ during the electrical stimulation of the striatum. The arrow indicates the time of stimulation of striatum $(0.1 \mathrm{~ms}$ pulse width; $10 \mathrm{~V})$. Post calibration of the carbon fiber electrode indicated that approximately $0.1 \mu \mathrm{M}$ dopamine is evoked by a single electrical stimulation in the dorsolateral striatum, peak rise time 0.5-1 s and half decay time approximately 0.75-1.25 s. E. Schematic diagram illustrating the placement of the carbon fibre microelectrode (recording electrode) and the bipolar stimulating electrodes in the dorsolateral striatum.

A sample and hold output before during and after a stimulus is shown in Figure 1D. Dopamine release under these conditions is tetrodotoxin-sensitive and $\mathrm{Ca}^{2+}$-dependent (Palij et al., 1990). Sample and hold data were recorded onto a computer via a 2 channel MacLab. Electrodes were calibrated with 
increasing concentrations of freshly prepared dopamine in the range $0.05 \mu \mathrm{M}$ to $1 \mu \mathrm{M}$, concentrations in the range of the endogenous dopamine released in the slices (see O'Neill \& O'Connor, 2008).

\subsection{Experimental Protocols}

Single pulse dopamine was stimulated every $2 \mathrm{~min}$ during the course of the experiment. Every 30 min a multiple pulse stimulation protocol was carried out (5 pulses at $10 \mathrm{~Hz}$ ). Dopamine $\mathrm{D}_{2}$ antagonists have previously been shown to increase this signal (Limberger et al., 1991) but not by others (Trout and Kruk, 1992). Two concentrations of caffeine and MDMA were applied to the slices; for caffeine, 30 min baseline control, $30 \mathrm{~min} 10 \mu \mathrm{M}$, and $30 \min 100$ $\mu \mathrm{M}$; for MDMA, 30 min baseline, $30 \mathrm{~min} 1 \mu \mathrm{M}$ and $30 \mathrm{~min} 30 \mu \mathrm{M}$ compound. For the combined protocol 1 and $10 \mu \mathrm{M}$ MDMA were each superfused for $30 \mathrm{~min}$ in the presence of $100 \mu \mathrm{M}$ caffeine.

\subsection{Drugs and Materials}

Artificial cerebrospinal fluid (aCSF) was prepared every day according to the following composition in $\mathrm{mM}: \mathrm{NaCl}, 120 ; \mathrm{KCl}, 2.5 ; \mathrm{MgSO}_{4}, 2 ; \mathrm{CaCl}_{2}, 2$; $\mathrm{NaH}_{2} \mathrm{PO}_{4}, 1.25$ and D-glucose, $10 \mathrm{mM}$ in $\mathrm{H}_{2} \mathrm{O}$. aCSF was bubbled with $95 \% \mathrm{O}_{2} / 5 \% \mathrm{CO}_{2}$. Caffeine (Sigma) and MDMA custom synthesized by G. Boland, Royal College of Surgeons in Ireland using the methods of Braun et al., (1980)) were dissolved in de-ionised water to a concentration of $10^{-2} \mathrm{M}$ and stored at $-20^{\circ} \mathrm{C}$ in $100 \mu \mathrm{L}$ volume containers. Compounds were used within 5 days of preparation.

\subsection{Data analysis}

All sample and hold data were analyzed and peak dopamine release measured at $4 \mathrm{~Hz}$. These values were exported into Excel sheets. Single pulse evoked dopamine overflow was measured as the peak release in response to electrical stimulation. Half decay time $\left(t_{1 / 2}\right)$ of dopamine release was measured from peak release to $50 \%$ half decay. Stimulated dopamine release was measured over 6 min (3 stimulations) prior to the first test drug application and the average of these 3 values were taken as $100 \%$. All values prior and subsequent to these were represented as \% control. Data are presented as means \pm standard error of the mean (s.e.m.) of $n$ independent experiments (brain slices from different animals). One-way ANOVA with post Bonferroni test was carried out in Figures 3 and 4 for the individual effects of caffeine and MDMA on single and 5 pulse stimulated dopamine release. In Figure $3 B$ and $D$ the Students paired t-test was used to calculate the effects of caffeine or MDMA on half decay times. In Figure 4 in order to analyze the interaction of caffeine and MDMA on dopamine release we used a 2-way ANOVA with post Bonferroni test. Calculations for single pulse dopamine release were based on the values from the last 10 minutes in each group. $\mathrm{P}<0.05$ was considered significant.

\section{RESULTS}

\subsection{Control experiments}

Single pulse dopamine release was evoked every 2 min (10V; $0.1 \mathrm{~ms}$ duration) and was stable for more than 3 hrs (Figure 2A). Typically evoked single pulse release ranged from 0.05 to $0.12 \mu \mathrm{M}$ dopamine when measured against the calibrated electrodes. Control rise times and half decay times ranged from 0.5 to 0.75 and 0.5 to $1 \mathrm{~s}$ respectively. 5 pulses at $10 \mathrm{~Hz}$ (multiple pulse stimulation; asterisks), was evoked every $30 \mathrm{~min}$ and was also stable for more than 3 hrs (Figure 2A and B).

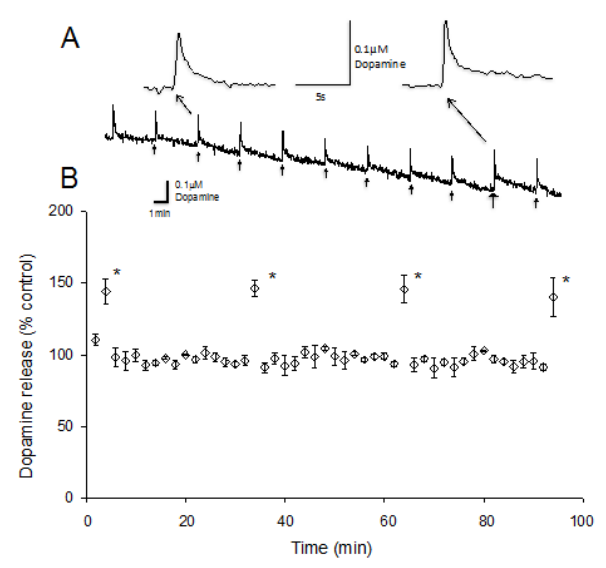

Figure 2. Control experiments carried out using fast cyclic voltammetry in slices of the rat striatum.

A. Typical sample and hold data trace showing single pulse stimulated $(10 \mathrm{~V}, 0.1 \mathrm{~ms})$ dopamine release every 2 min over a 20 min period (10 stimulations). The trace has been subjected to triangular (Bartlett) window (width 15) filtering (Chart 6.1). The arrows indicate the points of stimulation. The larger arrow towards the end of the trace indicates that a 5-pulse stimulation (at $10 \mathrm{~Hz}$ ) has been carried out. This was typically 1.4 to 1.6 times bigger than single pulse stimulation. Insets show on an extended timebase an example of a single pulse stimulated release of dopamine (left) and that of a 5 pulse stimulated response (right). B. Averaged time course data over a 90-min period. Asterisks indicate the occurrence of the 5-pulse protocol. Peak dopamine release was measured from the base to maximum peak post stimulation using Chart Zoom and exported to Excel ${ }^{\mathrm{TM}}$. The average of the last 3 values prior to compound application was taken as $100 \%$ and all values subsequent to these were represented as \% control (normalized). Data are presented as means \pm standard error of the mean (s.e.m.) of 5 independent experiments (different brain slices).

\subsection{Effects of caffeine or MDMA on single} and 5-pulse evoked dopamine release

Caffeine at $10 \mu \mathrm{M}$ had no significant effect on peak single or 5 pulse stimulated dopamine release. However $100 \mu \mathrm{M}$ caffeine caused a significant increase in peak stimulated 5 pulse dopamine release (Figure $3 A ; P<0.05, n=5$ ). Caffeine also caused a significant increase in 
the half decay time for both 1 pulse and 5 pulse stimulated dopamine release (Figure 3B; $\mathrm{P}<0.05$ for both). Both 1 and $30 \mu \mathrm{M}$ MDMA had significant effects on both peak single and 5pulse dopamine release (Figure $3 \mathrm{C} ; \mathrm{P}<0.001$ and $\mathrm{P}<0.05$ respectively; $\mathrm{n}=5$ for both). MDMA at both concentrations also significantly increased the half decay time $\left(\mathrm{t}_{1 / 2}\right)$ for single and 5 pulse dopamine release (Figure 3D and $D ; P<0.05, n=5$ for both single and 5 pulse stimulated dopamine release).

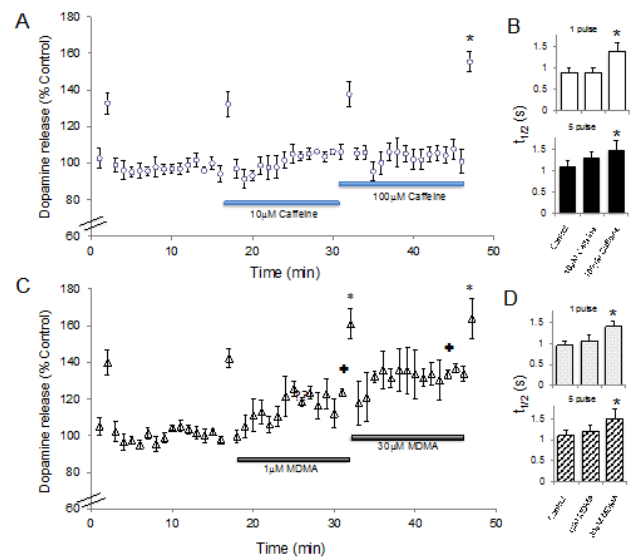

Figure 3. Effects of Caffeine or MDMA on stimulated dopamine release.

A. Averaged time course data showing the effect of $10 \mu \mathrm{M}$ and $100 \mu \mathrm{M}$ caffeine on peak single and 5-pulse stimulated dopamine release. The upper four points represent the 5-pulse protocol every $30 \mathrm{~min}$. Caffeine did not have any effect on single pulse release at both of the concentrations. However peak dopamine release evoked by 5 pulses at $10 \mathrm{~Hz}$ was significantly enhanced by 100 $\mu \mathrm{M}$ caffeine ( ${ }^{\star} \mathrm{P}<0.01$, compared to control). B. Averaged data for the effects of $10 \mu \mathrm{M}$ and $100 \mu \mathrm{M}$ caffeine on the half decay time $\left(t_{1 / 2}\right)$ of single pulse (white bars) or 5 pulse (black bars) stimulated dopamine release. $100 \mu \mathrm{M}$ caffeine significantly increased the half-time for reuptake for both 1 and 5 pulse stimulated release $(0.95 \pm 0.1$ to $1.4 \pm 0.13 \mathrm{~s}$ and $1.1 \pm 0.13$ to $1.5 \pm 0.24$, respectively, $\left.{ }^{*} \mathrm{P}<0.05, \mathrm{n}=5\right)$. C. Averaged time course data showing the effect of $1 \mu \mathrm{M}$ and $30 \mu \mathrm{M}$ MDMA on peak single and 5pulse stimulated dopamine release. The upper four points represent the 5-pulse protocol every $30 \mathrm{~min}$. MDMA gave rise to a significant increase in peak single pulse and 5 pulse evoked dopamine release at both concentrations (single pulse, ${ }^{+} P<0.01 ; 5$-pulse, ${ }^{*} P<0.05$, compared to control). D. Averaged data for the effects of $1 \mu \mathrm{M}$ and 30 $\mu \mathrm{M}$ MDMA on the half decay time $\left(\mathrm{t}_{1 / 2}\right)$ of single pulse (grey hatch bars) or 5-pulse (black hatch bars) stimulated dopamine release. $30 \mu \mathrm{M}$ MDMA significantly increased the half-time for reuptake for both 1 and 5-pulse stimulated release $(0.9 \pm 0.1$ to $1.4 \pm 0.21 \mathrm{~s}$ and $1.1 \pm 0.15$ to $1.5 \pm 0.21$, respectively, $\left.{ }^{*} P<0.05, n=5\right)$.

\subsection{Effects of a combination of caffeine and MDMA on dopamine release}

Perfusion of $100 \mu \mathrm{M}$ caffeine $30 \mathrm{~min}$ prior to the application of 1 and $30 \mu \mathrm{M}$ MDMA did not significantly change the effects of MDMA on single pulse stimulated dopamine release when compared to MDMA applied alone (Figure $4 \mathrm{~A}$ and $\mathrm{C} ; \mathrm{F}(1$, $10)=2.25, \quad P=0.127$, for MDMA alone versus caffeine+MDMA). Similar results were observed for 5 pulse stimulated dopamine release when caffeine and MDMA were co-applied (Figure 4D; $F(1$, 10) $=1.78, P=0.19$ ).
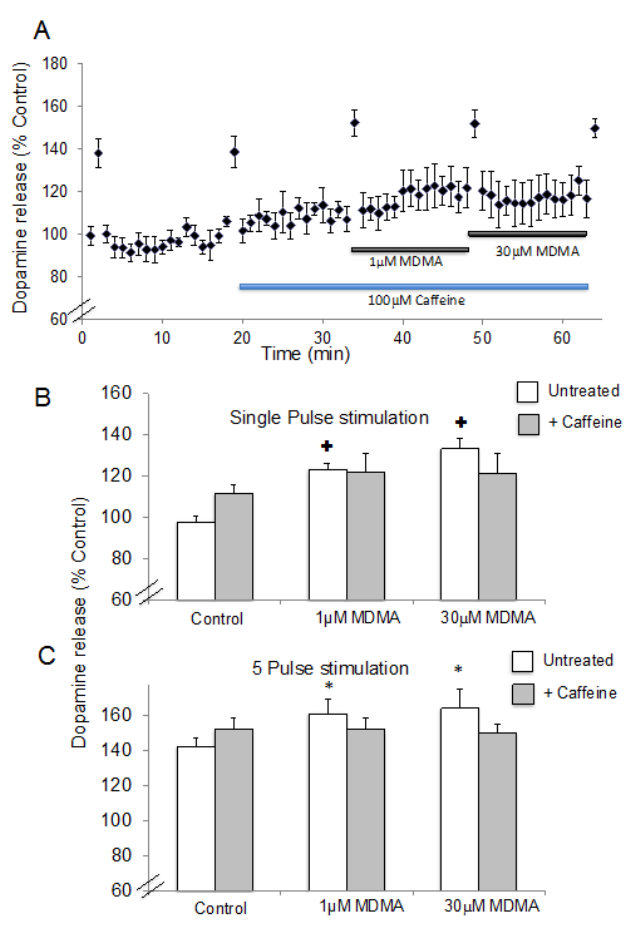

Figure 4. Effects of a combination of Caffeine and MDMA on stimulated dopamine release.

A. Averaged time course data showing the effect of $1 \mu \mathrm{M}$ and $30 \mu \mathrm{M}$ MDMA on single and 5-pulse stimulated dopamine release in the presence of $100 \mu \mathrm{M}$ caffeine. B. Summary bar graph showing the effects of MDMA alone and in combination with caffeine $(100 \mu \mathrm{M})$ on peak single pulse stimulated dopamine release. The data in Figure $3 \mathrm{C}$ and that above (A) have been compared here. Using a 2way ANOVA it was found that there was no significant interaction between caffeine and the effects of MDMA. C. Summary bar graph showing the effects of MDMA alone and in combination with caffeine $(100 \mu \mathrm{M})$ on 5-pulse stimulated dopamine release. The data in Figure $3 \mathrm{C}$ and that above $(A)$ have been compared here for 5-pulse data. Using a 2-way ANOVA it was found that there was no significant interaction between caffeine and the effects of MDMA.

\section{DISCUSSION}

In this study we have investigated whether application of caffeine (and activation of adenosine receptors) might interact synergistically with the effects of MDMA to modulate single or 5 pulse evoked release of dopamine from rat striatal slices. Whilst there is good evidence for an MDMA-related enhancement of dopamine release coupled to a caffeine-mediated antagonism of adenosine receptors using different methodologies to that used here, we show that prior addition of caffeine does not give rise to a greater effect of MDMA on dopamine release. In contrast to prior publications the present data were derived from experiments where dopamine $D_{2}$ autoreceptors are not activated by endogenous dopamine (Bull \& Sheehan, 1991). Limberger et al., (1991) has previously shown that dopamine $D_{2}$ auoreceptors are only activated by stimulated endogenous dopamine following electrical stimulation lasting a minimum of $200 \mathrm{~ms}$. As has previously been shown using the methodology of FCV (John \& Jones, 2007; Iravani et al., 2000) and other techniques (Gudelsky et al., 
1994; Fitzgerald and Reid, 1990; Johnson et al., 1986), we have also shown that MDMA applied alone enhances the amount of dopamine released and decreased the rate of its reuptake in striatal slices (increased reuptake time). We have also demonstrated, albeit at high concentrations, a stimulatory effect of caffeine on dopamine release as has also previously been demonstrated (Okada et al., 1997). However, the combination of caffeine and MDMA did not enhance the effect of either drug applied alone using our specific stimulation protocols.

In the rat striatum dopaminergic neurons are known to exhibit patterns of 'regular' (tonic) and high frequency 'burst' firing (Overton \& Clark, 1997) whereby action potentials can be generated singly or in bursts of up to ten to twenty. Electrical stimulation protocols can be designed to mimic either mode and examine their effects on dopamine release. In most studies, which in fact use burst firing or long durations of stimulation, there is a transient increase in extracellular dopamine while in other studies tonic firing may cause a new steadystate level of dopamine release (Venton et al., 2003). Previous work by Phillips \& Stamford, (2000) using a similar technique to that used in these experiments and similar brain regions, namely striatal slices, suggest that the dorsolateral caudate putamen comprises 'regular' neuronal firing, since it has more subtypes of presynaptic calcium channels and the medial axis of the dorsolateral caudate may respond more efficiently to 'burst' firing. This is consistent with the observed function in these regions, where significantly greater dopamine efflux is measured in the medial axis than in the dorsolateral caudate putamen for high frequency train stimulations. In this study we have used discrete single-pulse stimulation in the dorsolateral region of the striatum, which is likely to be similar to regular neuronal firing. The use of high frequency pulse stimulations would approximate bursts of electrical activity in these cells but would in the process activate $D_{2}$ autoreceptors. Whether this alone might account for the differences in the effect of caffeine/MDMA on dopamine release remains to be determined. We have also shown that the 5 single pulses delivered at $10 \mathrm{~Hz}$ gave rise to dopamine release that was not further affected by application of both compounds. Even thought this represents a train stimulation lasting $400 \mathrm{~ms}$ and presumably some $D_{2}$ autoreceptor activation, we do not believe it is a strong stimulation and that the frequency of delivery is low (see Trout \& Kruk, 1992).

It has been suggested that caffeine may facilitate MDMA toxicity predominately by the activation of dopamine $D_{1}$ receptors (Vanattou-Saïfoudine et al., 2012a,b; Mohamed et al., 2011; VanattouSaiifoudine et al., 2010b). Also mice that have been administered caffeine $(10 \mathrm{mg} / \mathrm{kg})$ prior to MDMA (5 $\mathrm{mg} / \mathrm{kg}$ ) show a potentiated MDMA-induced locomotor activity (Camarasa et al., 2006). Therefore overall it has been hypothesized that caffeine blocks adenosine $A_{2}$ receptors, potentiating dopamine release and increasing MDMA-related hyper locomotion (Camarasa et al., 2006). Moreover, caffeine may act via inhibition of adenosine $A_{1}$ receptors to increase MDMA-induced striatal dopamine release (Vanattou-Saïfoudine et al., 2011). Also we have previously shown using similar techniques to those carried out here that dopamine $D_{1}$ receptors play a role in the inhibition of dopamine by $A_{1}$ receptor activation (O'Neill et al., 2007).

Our studies involved the administration of MDMA acutely onto rat brain slices. It is accepted that acute behavioral and body temperature changes in rat and humans result from rapid MDMA-induced monoamine release, whereas long-term neurotoxicity is primarily caused by metabolites of the drug (Albers \& Sonsalla, 1995; Green et al., 2012). In these preliminary experiments we did not investigate any of these metabolites and their interaction with caffeine. It also seems that plasma MDMA concentrations and functional outcome are similar in rats and humans at low dose administration but not at high concentrations (Green et al., 2012). Therefore acute application of MDMA may not be comparable to in vivo human studies where metabolites are formed (Baumann et al., 2009). Finally the rate of metabolism of MDMA and its major metabolites is slower in humans than in rats and this may have to be considered when utilizing rat models.

In conclusion whilst there is unequivocal evidence that caffeine acts synergistically with MDMA on dopamine release, this effect is not seen when dopamine is evoked by single and 5 pulse stimulation.

\section{Acknowledgements}

We would like to thank Science Foundation Ireland, Enterprise Ireland (CF20122777Y) and University College Dublin for financial support, M Dalton for technical assistance and $\mathrm{G}$. Braun for the synthesis of MDMA.

\section{REFERENCES}

Antoniou, K., Papadopoulou-Daifoti, Z., Hyphantis, T., Papathanasiou, G., Bekris, E., Marselos, M., Panlilio, L., Müller, C.E., Goldberg, S.R., Ferré, S., 2005. A detailed behavioral analysis of the acute motor effects of caffeine in the rat: involvement of adenosine $A 1$ and A2A receptors. Psychopharmacol. 183, 154-162.

Albers, D.S., Sonsalla, P.K., 1995. Methamphetamineinduced hyperthermia and dopaminergic neurotoxicity in mice: pharmacological profile of protective and nonprotective agents. J. Pharmacol. Exp. Ther. 275, $1104-1114$.

Baumann, M.H., Zolkowska, D., Kim, I., Scheidweiler, K.B., Rothman, R.B., Huestis, M.A., 2009. Effects of dose and route of administration on pharmacokinetics of ( \pm )-3,4-methylenedioxymethamphetamine (MDMA) in the rat. Drug Metab. Dispos. 37, 2163-2170.

Braun, U., Shulgin, A.T., Braun, G. 1980. Centrally acting $\mathrm{N}$-substituted analogs of $3,4-$ methylenedioxyphenylisopropylamine $\quad(3,4-$ methylenedioxy methamphetamine). J. Pharm. Sci. 69, 192-195.

Bull, D.R., Sheehan, M.J., 1991. Presynaptic regulation of electrically evoked dopamine overflow in nucleus accumbens: a pharmacological study using fast cyclic voltammetry in vitro. Naunyn Schmiedebergs Arch Pharmacol. 343: 260-265.

Camarasa, J., Pubill, D., Escubedo, E., 2006. Association of caffeine to MDMA does not increase antinociception but potentiates adverse effects of this recreational drug. Brain Res. 1111, 72-82.

Crespi, D., Mennini, T., Gobbi, M., 1997. Carrier- 
dependent and $\mathrm{Ca}(2+)$-dependent 5-HT and dopamine release induced by (+)-amphetamine, 3,4methylendioxymethamphetamine,

chloroamphetamine and (+)-fenfluramine. $\mathrm{Br}$. J. Pharmacol. 121, 1735-1743.

Derlet, R.W., Tseng, J.C., Albertson, T.E., 1992. Potentiation of cocaine and d-amphetamine toxicity with caffeine. Am. J. Emerg. Med. 10, 211-216.

Ferré, S., Ciruela, F., Borycz, J., Solinas, M., Quarta, D. Antoniou, K., et al. 2008a. Adenosine A1-A2A receptor heteromers: new targets for caffeine in the brain. Front. Biosci. 13, 2391-2399.

Ferré, S., Quiroz, C., Woods, A.S., Cunha, R., Popoli, P., Ciruela, F., Lluis, C., Franco, R., Azdad, K., Schiffmann, SN. 2008b. An update on adenosine A2A-dopamine D2 receptor interactions: implications for the function of $\mathrm{G}$ protein-coupled receptors. Curr Pharm Des. 14:1468-74.

Fitzgerald, J.L., Reid, J.J., 1990. Effects of methylenedioxymethamphetamine on the release of monoamines from rat brain slices. Eur. J. Pharmacol. 191, 217-20.

Green, A.R., King, M.V., Shortall, S.E., Fone, K.C., 2012. Lost in translation: preclinical studies on 3,4methylenedioxymethamphetamine provide information on mechanisms of action, but do not allow accurate prediction of adverse events in humans. $\mathrm{Br} J$ Pharmacol. 166, 1523-1536.

Green, A.R., Mechan, A.O., Elliott, J.M., O'Shea, E. Colado, M.I., 2003. The pharmacology and clinica pharmacology of 3,4-methylenedioxy methamphetamine (MDMA, "ecstasy"). Pharmacol Rev. 55, 463-508.

Green, A.R., Cross, A.J., Goodwin, G.M., 1995. Review of the pharmacology and clinical pharmacology of 3,4methylenedioxy-methamphetamine (MDMA

'Ecstasy'). Psychopharmacol. 119, 247-260.

Gudelsky, G.A., Yamamoto, B.K., Nash, J.F., 1994 Potentiation of 3,4-methylenedioxymethamphetamineinduced dopamine release and serotonin neurotoxicity by $5-\mathrm{HT} 2$ receptor agonists. Eur. J. Pharmacol. 264, 325-330.

Ikeda, R., Igari, Y., Fuchigami, Y., Wada, M., Kuroda, N. Nakashima, K., 2011. Pharmacodynamic interactions between MDMA and concomitants in MDMA tablets on extracellular dopamine and serotonin in the rat brain. Eur. J. Pharmacol. 660, 318-325.

Iravani, M.M., Asari, D., Patel, J., Wieczorek, W.J., Kruk, Z.L., 2000. Direct effects of 3,4 methylenedioxymethamphetamine (MDMA) on serotonin or dopamine release and uptake in the caudate putamen, nucleus accumbens, substantia nigra pars reticulata, and the dorsal raphé nucleus slices. Synapse. 36, 275-85.

John, C.E., Jones, S.R., 2007. Voltammetric characterization of the effect of monoamine uptake inhibitors and releasers on dopamine and serotonin uptake in mouse caudate-putamen and substantia nigra slices. Neuropharmacol. 52, 1596-1605.

Johnson, M.P., Hoffman, A.J., Nichols, D.E., 1986. Effects of the enantiomers of MDA, MDMA and related analogues on $[3 \mathrm{H}]$ serotonin and $[3 \mathrm{H}]$ dopamine release from superfused rat brain slices. Eur. J. Pharmacol. 132, 269-276.

Limberger, N., Trout, S.J., Kruk, Z.L., Starke, K., 1991. "Real time" measurement of endogenous dopamine release during short trains of pulses in slices of rat neostriatum and nucleus accumbens: role of autoinhibition. Naunyn Schmiedebergs Arch Pharmacol. 344, 623-629.

Lyles, J., $\quad$ Cadet, J.L., 2003 Methylenedioxymethamphetamine [MDMA, ecstasy] neurotoxicity: cellular and molecular mechanisms. Brain Res. Rev. 42, 155-168.

Mango, D., Bonito-Oliva, A., Ledonne, A., Cappellacci, L., Petrelli, R., Nisticò, R., Berretta, N., Fisone, G.,
Mercuri, N.B. 2014. Adenosine A1 receptor stimulation reduces D1 receptor-mediated GABAergic transmission from striato-nigral terminals and attenuates I-DOPA-induced dyskinesia in dopaminedenervated mice. Exp Neurol. 2014, 261:733-43.

McNamara, R., Kerans, A., O'Neill, B., Harkin, A., 2006. Caffeine promotes hyperthermia and serotonergic loss following co-administration of the substituted amphetamines, MDMA ("Ecstasy") and MDA ("Love") Neuropharmacol. 50, 69-80.

Millar, J., Barnett, T.G., 1988. Basic instrumentation for fast cyclic voltammetry. J. Neurosci. Methods. 25, 9195.

Mohamed, W.M., Ben Hamida, S., Cassel, J.C., de Vasconcelos, A.P., Jones, B.C., 2011. MDMA: interactions with other psychoactive drugs. Pharmacol. Biochem. Behav. 99, 759-774.

O'Connor, J.J., Lowry, J.P., 2012. A comparison of the effects of the dopamine partial agonists aripiprazole and (-)-3-PPP with quinpirole on stimulated dopamine release in the rat striatum: Studies using fast cyclic voltammetry in vitro. Eur. J. Pharmacol. 686, 60-65.

Okada, M., Kiryu, K., Kawata, Y., Mizuno, K., Wada, K., Tasaki, H., Kaneko, S., 1997. Determination of the effects of caffeine and carbamazepine on striatal dopamine release by in vivo microdialysis, Eur. $\mathrm{J}$. Pharmacol. 321, 181-188.

O'Loinsigh, E.D., Boland, G., Kelly, J.P, O'Boyle, K.M., 2001. Evidence for a critical role of body temperature in the modulation of MDMA neurotoxicity by drugs of abuse. Brit. J. Pharmacol. 143, 151P.

O'Neill, C., Nolan, B.J., Macari, A., O'Boyle, K.M. O'Connor, J.J., 2007. Adenosine A1 receptormediated inhibition of dopamine release from rat striatal slices is modulated by D1 dopamine receptors. Eur J Neurosci. 26, 3421-3428.

O'Neill, C., O'Connor, J.J., 2008. An investigation into the influence of NMDA and GABA on the modulation of electrically stimulated dopamine release by adenosine in the rat striatum: studies using fast cyclic voltammetry. Sensors 8, 5229-5237.

Overton, P.G., Clark, D., 1997. Burst firing in midbrain dopaminergic neurons. Brain Res. Rev. 25, 312-334.

Palij, P., Bull, DR., Sheehan, M.J., Millar, J., Stamford, J., Kruk, Z.L., Humphrey, P.P., 1990. Presynaptic regulation of dopamine release in corpus striatum monitored in vitro in real time by fast cyclic voltammetry. Brain Res. 509, 172-174.

Phillips, P.E., Stamford, J.A., 2000. Differential recruitment of $\mathrm{N}$-, $\mathrm{P}$ - and Q-type voltage-operated calcium channels in striatal dopamine release evoked by 'regular' and 'burst' firing. Brain Res. 884, 139-146.

Quarta, D., Ferre, S., Solinas, M., You, Z.B., Hockemeyer, J., Popoli, P., Goldberg, S.R., 2004. Opposite modulatory roles for adenosine $\mathrm{A} 1$ and $\mathrm{A} 2 \mathrm{a}$ receptors on glutamate and dopamine release in the shell of the nucleus accumbens. Effects of chronic caffeine exposure. J. Neurochem. 88, 1151-1158.

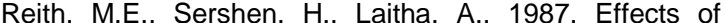
caffeine on monoaminergic systems in mouse brain. Acta Biochim. Biophys. Hung. 22, 149-163.

Sinchai, T., Plasen, S., Sanvarinda, Y., Jaisin, Y. Govitrapong, P., Morales, N.P., Ratanachamnong, P., Plasen, D., 2011. Caffeine potentiates methamphetamine-induced toxicity both in vitro and in vivo. Neurosci. Lett. 502, 65-69.

Solinas, M., Ferré, S., You, Z.B., Karcz-Kubicha, M. Popoli, P., Goldberg, S.R., 2002. Caffeine induces dopamine and glutamate release in the shell of the nucleus accumbens. J. Neurosci. 22, 6321-6324.

Stamford, J.A., 1990. Fast cyclic voltammetry: measuring transmitter release in 'real time'. J. Neurosci. Methods. 34, 67-72

Trout, S.J., Kruk, Z.L., 1992. Differences in evoked dopamine efflux in rat caudate putamen, nucleus accumbens and tuberculum olfactorium in the 
absence of uptake inhibition: influence of autoreceptors. Br. J. Pharmacol. 106, 452-458.

Vanattou-Saïfoudine, N., Behan, B., Harkin, A., 2012a. Dopamine D1 receptor-mediated intracellular responses in the hypothalamus after co-administration of caffeine with MDMA. Basic Clin. Pharmacol. Toxicol. 110, 283-289.

Vanattou-Saïfoudine, N., McNamara, R., Harkin. A. 2012b. Caffeine provokes adverse interactions with 3,4-methylenedioxymethamphetamine (MDMA, 'ecstasy') and related psychostimulants: mechanisms and mediators. Br. J. Pharmacol. 167, 946-959.

Vanattou-Saïfoudine, N., Gossen, A., Harkin, A., 2011. A role for adenosine $A(1)$ receptor blockade in the ability of caffeine to promote MDMA "Ecstasy"-induced striatal dopamine release. Eur. J. Pharmacol. 650, 220-228.

Vanattou-Saïfoudine, N., McNamara, R., Harkin, A. 2010a. Mechanisms mediating the ability of caffeine to influence MDMA ('Ecstasy')-induced hyperthermia in rats. Br. J. Pharmacol. 160, 860-877.

Vanattou-Saïfoudine, N., McNamara, R., Harkin, A., 2010b. Caffeine promotes dopamine D1 receptormediated body temperature, heart rate and behavioural responses to MDMA ('ecstasy'). Psychopharmacol. 211, 15-25.

Venton, B.J., Zhang, H., Garris, P.A., Phillips, P.E., Sulzer, D., Wightman, R.M., 2003. Real-time decoding of dopamine concentration changes in the caudateputamen during tonic and phasic firing. J. Neurochem. $87,1284-1295$ 